today will remember the inspiration they were given by those who mentored, challenged and supported them as social work students venturing out into practice for the first time.

Fulcher's article has been chosen for inclusion in this retrospective journal not only to revitalise debate and discussion about the place of the practice curriculum in social work education but also to acknowledge and celebrate the work of past and present fieldwork educators across Aotearoa New Zealand.

\title{
Putting the baby back in the bathwater: Re-thinking the practice curriculum in social work education
}

\section{Leon C Fulcher}

Leon Fulcher is the former Director of Social Work Education at the University of Stirling in Scotland where he began his teaching career as a Lecturer in Social Work in 1975. He has practised and supervised staff in the United States, Canada and the United Kingdom. His research in the fields of social work and group care has maintained an international perspective, focusing on services and educational programmes in the United Kingdom, Western Europe, Israel, North America and Australasia. He is co-editor of Group Care for Children: Concept and Issues and Group Care Practice with Children, both published by Tavistock. He is currently Professor of Social Work at Victoria University, Wellington, New Zealand. This paper was presented at the twentieth national conference of the Australian Association of Social Workers, 1987.

\section{Introduction}

The demands on professional education are many if social workers are to respond effectively to the tasks expected of them in a rapidly changing society. While supervised practice has been a feature of social work education for many years, its place in the overall curriculum has become increasingly compromised. Many educational institutions have imposed constraints on the scheduling of placements by timetabling classes in such a way as to ensure that supervised practice can only be obtained during holiday periods outside the normal academic year. Traditional academic interests have tended to dictate the content of assessment so that theoretical learning has been emphasised at the expense of applied learning. Methods of assessment have tended to focus on essay construction and periodic examinations, with practice studies often being seen as a soft option. Finally, limited attention has been given to the development of practice teaching with the result that placement supervision is obtained from anyone with qualifications and experience, regardless of practice teaching ability.

It is little wonder then that, on completion of qualifying education, many intending social workers are ill-equipped to deal with the day-to-day demands of professional practice. Such 
practitioners frequently have a trained incapacity to function in the complex organisations which now supply social work services. They lack both the competence and the confidence to operate successfully in the turbulent social policy environment which surrounds contemporary practice. All too often, the beginning practitioner relies on a broad ideological perspective which assumes that the complex structures of social control are the sources of all evil in our society; therefore, all interventions must be directed towards challenging these structures.

Several historical and ideological influences have contributed to the current state of affairs in social work education, especially the weakened position of supervised practice in the qualifying curriculum. Some of these influences will be examined in what follows in arguing that applied learning needs to regain a more central position in the professional education of social workers. First, attention is given to the great expectation that society has held for social workers since the 1960s. Next, consideration is given to different educational approaches that have been prominent in professional education, before identifying several challenges which have been directed at professional education. The attention focuses on the practice curriculum in professional education for social work. Finally, implications for social work practice in a changing society are identified and discussed.

\section{Great expectations for social workers.}

Much is expected of social workers in contemporary society. Legislative changes in most Western societies since the mid-1960s have imposed major expectation, emphasising the extent to which social workers are expected to deal with major social concerns in an increasingly complex world. Other professions, such as law, medicine, teaching and the police, have voiced their expectations too - along with their concerns - about the introduction of social workers into areas of work which have been their traditional domain. Associated tension have been noted by the media, especially when social work clients have dared to commit crimes, become the victims of physical or sexual abuse, or suffer physical neglect because of poverty, inadequate housing or disability. One might well ask why social workers are willing to take on many of the tasks which society now expects of them. Such expectations, once lauded in idealistic terms, have now become major social burdens for the profession of social work. Almost everyone is ready to point out how social work has failed to meet these expectations but few seem to acknowledge the reasons why this might be so.

Situations involving child abuse and neglect are perhaps the most sensitive area of the practice in which society expects the social workers to become involved. Another contentious area of social work practice is that which involves the control and rehabilitation of offenders. Similar problems must be confronted when social workers intervene in the lives of people suffering from mental illness. While the legal expectations may be different (except in relation to the criminally insane), the social expectations on workers in this field are still enormous (Brown, Bute and Ford, 1986). In each of these areas of practice - child abuse, work with offenders and work with the mentally ill - there is also a growing demand for cultural sensitivity. One cannot escape the fact that certain minority groups are over-represented in the health, welfare and prison populations that are of concern to social workers. Major demands are made on social workers in supporting disabled or intellectually handicapped people to live comparatively normal lives in the community. Advocacy for those who suffer the consequences of forced redundancy is another undervalued activity in which social 
workers become engaged. In the extreme, consider the challenge facing social workers in Northern Ireland, who must decide whether to report the paramilitary activities of clients whom they are charged to assist.

This should remind us just how challenging the tasks of social work can be. The expectations placed on social workers are great, whether they come from legislation, public demands or from the specific requests of individuals, families and community groups. In the face of these expectations, it is not surprising that many social workers struggle just to 'keep their heads above water'. It is easy to conclude that social workers are an expendable commodity who, on completion of training, are left to their own devices to survive and be marginally effective or to sink without trace by leaving the profession to take up less demanding pursuits. Our argument is that professional education must take some responsibility for these circumstances.

\section{Different approaches to professional education}

Different educational approaches have been influential in the professional training of social workers. However, no one particular educational approach has found universal appeal. Rather, various combinations of approach have been used by different professions to prepare aspiring candidates for practice in a given discipline.

Perhaps the oldest approach to professional education has been the pattern where aspiring candidates were 'taken on' by a fully qualified person for a lengthy period of apprenticeship training. With increasing specialisation, apprenticeship training gradually gave way to the classroom plus laboratory approach. It is interesting to note that the classroom plus laboratory approach was influenced by at least two types of specialisation. Professional specialisation helped to encourage this approach as did specialisation in the field of education generally. A third approach to professional education involved correspondence training. This approach found considerable appeal at a time when fewer educational centres were available and when professional education was required by those living in geographically isolated areas.

Some groups have relied very extensively on in-service training as the preferred approach to professional education. The profession of nursing is a particular case in point, along with other health-related professions such as physiotherapy. A fifth approach that has influenced professional education involves the liberal arts orientation. This approach assumes that candidates to any profession require a period of foundation learning which offers introduction to the arts, humanities, and sciences prior to professional specialisation.

A sixth educational approach which has gained favour in recent years is concerned with distance learning. As the cost of professional education has increased, so too has the interest in distance learning approaches grown. Advances in the field of educational technology have meant that a vast array of audio, video and computerised materials have become available to assist professional workers to keep abreast of new advances in their fields. It has been argued that distance learning presents a major challenge for the future development of professional education (Osborne, 1983). Unless professional educators openly confront the dual challenge for public accountability and practice relevance then distance learning approaches are likely to gain favour as an attractive and cheaper alternative to the traditional education programme. 
It can be seen that each of these approaches has been influential to some extent in the development of professional education for social work. In each approach, supervised practice is emphasised in different ways. Some approaches start with the practice setting and endeavour to build in formal educational opportunities. Other approaches start by providing formal educational opportunities and then try to build in practical experience. At a time when major challenges are being directed at professional education and practice generally, then careful attention needs to be given to the place of supervised practice in any educational programme. Lest the baby be thrown out with the bathwater, professional educators can ill afford to ignore the challenges being raised by the very public they claim to support.

\section{Modern challenges to professional education}

A number of challenges have been directed at professional education in recent years. Such challenges have come from a variety of sources and reflect different aspects of the changing society in which we live. As educators seek to respond to these challenges, so the frequent result has been to make adjustments in one part of the curriculum, only to find that the challenges have intensified in relation to other parts of the curriculum. By examining several contemporary challenges, it is hoped that the case for a more comprehensive approach to the curriculum change will be substantiated.

Major challenges have been directed at professional education for failing to address the issue of gender in professional practice. It is argued that all professions are dominated by a patriarchal orientation and the women frequently receive services that are insensitive to their needs as a significant population. As the population of those ages 65 and over increases steadily, so ageism also represents a major challenge to the health and welfare professions. While elderly people were venerated in many traditional societies, their position in contemporary society is increasingly undermined by attitudes and policies which view elderly people as being no longer 'economically productive'. The cry for culturally appropriate interventions can be heard throughout the Southern Hemisphere as professional workers seek to contend with different, and at times contradictory, world views which require substantially different approaches to practice. Recent developments in Fiji and New Zealand, and to a lesser extent Australia, have highlighted the unique political position of indigenous peoples and their claim that traditional culture and lifestyles have been systematically ignored in professional education. Indeed, it is argued that professional education is very much a part of the institutional structures of racism which must be addressed if distinctive minority groups are to obtain full recognition in a rapidly changing society (Rangihau, 1986).

Challenges from each of the above sources - whether concerning gender, ageism or cultural insensitivity - reflect a wider challenge associated with consumerism and the demand for increased accountability. Court actions associated with malpractice, appeals for disciplinary action through professional associations and the emergence of community initiatives which challenge traditional professional roles are all indicative of the way that increased accountability is now being demanded. The public is no longer willing to passively accept decisions being made on their behalf. Consumer interests have influenced social policy to the extent that one sees the decentralisation of services, normalisation in the way services are offered and a general emphasis on community care. However, what is less apparent is the extent to which economic policies have been influential in shaping these social policies in subtle but significant ways (Scull, 1977). 
The demand for increased accountability and greater appreciation of consumer interests is not unrelated to a fifth challenge directed at professional education, involving the call for efficiency in public spending and cost effectiveness. As public expenditure on health, education and welfare services has increased as a percentage of gross national products, so the calls for increased efficiency in the these fields have also increased. Major economies are now being sought as governments challenge professional workers to work harder with fewer resources. Reorganisation has become a catch phrase in virtually all the professions, given the expectation that greater efficiency - and savings - will be achieved by organising the system in a different way. An elusive goal in all this is that services should also be 'cost effective'. Many still confuse the two concepts of efficiency and effectiveness, with most failing to note that efficiency is a measure of how resources actually get used while effectiveness is a measure of the outcomes produced. This distinction is critical since effectiveness in some aspects of professional practice may be comparatively inefficient.

This highlights a sixth challenge that is being directed at professional education, involving measurement of outcomes. This rise of evaluation research in all sectors of professional practice is closely related to the demand for outcome measurement. Most agree with Knapp (1985) that outcome measurement is far more complicated in the social care fields than in most other areas of professional practice, notably accountancy.

If outcomes are measured at the level of individual services then the results may indicate reduced efficiency at the same time as emphasising service effectiveness. If outcomes are measured at the level of a particular programme of services then increased efficiency may be achieved at the expense of service effectiveness for individual recipients. The demand for outcome measurement in the current economic climate highlights the extent to which intending practitioners must learn more than the techniques and methods of outcome measurement. They need also to learn about how the social policy environment influences the extent to which outcome measurement is now required more than at any other time in history.

It is in this sense that the importance of both training and education for professional practice is highlighted: training in how to carry out particular tasks is required, along with education about why such tasks are now required as a feature of professional practice. All these challenges to professional education are grounded in the daily dilemmas of professional practice for social work which have been our concern throughout this paper. If social workers are to be equipped, both intellectually and practically, to address these issues then social work education requires a clearer commitment to practice learning as a central feature of the educational endeavour. The practice curriculum must become the primary focus of attention in all that the professional educators do, so as to ensure that aspiring candidates are both educated and trained to perform effectively and efficiently in their chosen fields of practice.

\section{The practice curriculum and its place in the wider curriculum}

When looking at the practice curriculum in professional education, our assumption is that learning must be capable of translation into a practical language that can be used by workers in the course of their daily work. To this end, I accept the Marxist proposition that:

Social life is essentially practical. All mysteries which lead theory to mysticism find their rational solution in human practice and in the comprehension of this practice... Philosophers 
have only interpreted the world, in various ways, the point is to change it (Livingstone and Benton, 1975, p. 43).

The practice curriculum is therefore concerned with the applications of theory in action(s), or praxis. Such an orientation draws attention to the dual challenge in professional education, referred to by Casson as 'the need to acquire knowledge about the world and the need to develop knowledge for acting in the world' (1982, pp. 14-23). Both aspects of this educational challenge need to be addressed when devising the practice curriculum in professional education.

Classical education for children and for adults has stressed the acquisition of knowledge and the transmission of received wisdom. As such, education has remained essentially subject centred. This may be appropriate for some types of education where certain groups or individuals are seeking to maintain particular traditions. It is not appropriate, however, for adults who will be expected to take professional responsibility for their own actions nor for workers who are expected to contribute to the development of professional services based on continuously evolving concepts of professional practice. This requires an adult oriented and learner centred approach to professional education instead of a subject centred approach (Knowles, 1978).

Several guiding principles have been identified in developing a learner centred approach to professional education (Kinloch and Fulcher, 1984). Some of these guiding principles can be listed as follows:

- Adults are more interested in learning when it is perceived as relevant by them.

- Life experience provides a rich resource from which to learn, and on which to build, in becoming more skilled and sensitive professional practitioners.

- Performance on the job, along with confidence and satisfaction in the job will improve if adults are helped to analyse and identify what they already know.

- An examination of concrete day-to-day experiences of practice provides rich material from which adults learn to make conscious choices about their actions.

- Learning from individual and small group discovery is particularly relevant for people whose daily task is to seek out and develop the potential of individuals or groups of clients, and to work as members of staff teams.

- Student participation in learning provides a model which reflects the concept of client participation in professional practice.

- Learning can produce both excitement and anxiety at the prospect of changing. For this reason, a climate which is most likely to aid learning is one which offers support and safety to test out ideas and their application without too much threat to self esteem.

- The most difficult stage in the learning process is that involving generalisation from one situation to another. Until this cycle has been completed, any learning which has taken place is not much use in practice. Grasping and understanding an idea in one situation represents a first stage. Most people need tuition/ supervision over time to transfer what has been learned from one situation to other situations. The sophistication of this process tends to be underestimated with the result that, often, too much is expected from the learner too soon.

- Specific study skills may have to be acquired if adults have not previously undertaken tertiary education. Motivation for development of study skills often springs from a desire 
to achieve specific personal and professional goals.

- Among adults there are important differences in style, timing and pace of learning which need to be taken into account when designing programmes of professional education (Ibid, pp. 37-38).

Differences in learning style are especially important when considering the practice curriculum in professional education. It is important to bear in mind, however, that learning styles are not fixed and unchangeable. Many adults approach the tasks of professional education with an inductive learning style. For them, the logical process of learning is to move from particular experiences to general principles, which are embedded in those experiences. The practice curriculum needs to offer opportunities for those with inductive learning styles to use day-to-day experiences more consciously and constructively. Through the use of regular supervision or practice teaching opportunities, the inductive learner is given opportunities to generalise learning and apply specific principles to par-tertiary education, approach profescially (sic) those with greater experience in tertiary education, approach professional education with a deductive style to learning. With this learning style, new ideas need to be fully understood before they have any relevance for application in practice. Given that most courses will have both inductive and deductive learning styles represented amongst the candidates receiving professional training, it is important that practice teaching should take account of these variables.

It is not sufficient, however to design the practice curriculum on the basis of subjectversus learner-centred approaches or by taking account of the different learning styles which candidates bring to professional education. It is also necessary to take account of the organisational context in which professional practice is offered. Those who have organised the practice curriculum around a two or three days per week 'concurrent' placement have tended to ignore the organisational context of practice. While the concurrent placement has allowed for lengthy periods of supervised practice which extend throughout an academic year, such an arrangement has frequently prevented candidates from attending the weekly team meeting, or addressing other demands which fall outside the normal placement period. The practice learning available in this pattern may emphasise sustained professional contact with clients at regular intervals over the course of several months, but it tends to leave workers under-equipped to perform as part of a wider professional team. In organisational terms, the concurrent pattern of placement tends to reinforce a 'part-time' orientation to practice which is largely inconsistent with the daily realities of professional practice in most fields. Thus, the very pattern adopted for the practice curriculum may contribute to a 'trained incapacity' on the part of those who obtain a professional education.

The practice curriculum which adopts a 'block' pattern helps to overcome some of these organisational problems at the same time that other limitations are presented. The advantages of a block pattern are that a candidate becomes a full time member of a service agency or team, even though membership is acknowledged to be at a relatively low status. Provided that the block placement extends for a 'long enough' period to ensure a candidate can engage in most - if not all - of the professional tasks expected of workers in that setting, then practice learning is more likely to prepare candidates for the daily tasks of professional practice. A limitation of the block placement, however, is that it does not allow for sustained involvement over several months with particular clients or groups, such as might be required in some therapeutic environments of community development projects. This limitation is 
to some extent ameliorated by the way it helps to focus attention on both the demands of direct practice with specific individuals and groups and indirect practice associated with agency administration, the organisational context and the social policy environment which surround professional practice (Ainsworth, 1981; 1984). It can be argued that such an ecological perspective (Bronfenbrenner, 1979) helps to prepare intending professionals more adequately for the realities and demands of daily practice. It also helps to focus attention on features of professional practice which had traditionally been ignored in most educational programmes (Millham, Bullock and Hosie, 1980).

And yet, regardless of the important structural elements which influence the practice curriculum, experience has shown that the availability of good practice teaching or supervision during placement is also of paramount importance. Syson's study of practice learning for social work called attention to the way in which many practice teacher or placement supervisors had no contact with professional courses other than by having a student on placement (1981, p. 132). Student supervision is normally accorded low status within practice agencies and this too affects the quality of practice learning which intending professionals may obtain. Factors, such as lack of training for supervision, workloads not being reduced, lack of supervision for the practice teacher, lack of facilities to enable placements to be carried out properly and restricted access to work deemed suitable for students were all highlighted in the Syson study (1981, p. 151).

If the practice curriculum is to prepare candidates for the rigors of professional practice then agency-based practice teachers must attend to a number of concerns (Syson, 1981, p. 152). First, it is necessary to ensure that facilities for the student and for practice supervision are available and are as good as circumstances will allow. Second, the practice teacher needs to brief other members of staff about the student's arrival and foster a generally welcoming attitude within the agency. Third, the practice teacher must clarify the procedures for obtaining work for students. Fourth, they should be able to negotiate for a reduced workload so as to allow time for supervision, visits to the tertiary education centre and appropriate reading. Finally, the practice teacher must ask for (or demand where necessary) training and supervision as a practice teacher.

Syson concluded that five educational factors were essential ingredients for success in the practice curriculum of social work (1981, p. 165). These were:

- Formulation of at least a rough plan for the whole - or different stages - of the placement.

- Work being available which is suited to the student's educational needs, and enough of it.

- Hard work from the student to make the most of opportunities that arise.

- Hard work from the practice teacher giving time and thought to the student and using supervision for constructive, not destructive criticism, together with an ability to look at broader issues than simply progress on the tasks in hand.

- Good relationship between student and practice teacher, preferably with contact or at least accessibility between supervision sessions.

Other factors which were thought to enhance the chances of success on placement were also noted. Early discussion and consultation about placements between course tutors and students were recommended. Pre-placement visits to the placement by student and course 
tutor together were also considered important. To the extent possible, a clear definition of expectations for a student, practice teacher and course tutors should be established to form the basis for a 'working contract' during the placement. Support for the practice teacher and interest in the student from colleagues, line managers and others connected with the agency were also emphasised. Finally, reasonable space needs to be available for the student in terms of having a place where they can keep their belongings, obtain access to a telephone or find secretarial assistance. If space of this type is not available then some explanation should be available about why this is the case.

One final concern involves assessment. Traditional classroom assessment based on essays and examinations tends to have limited value in practice learning. Placement evaluations carried out at the end of a period of supervised practice is one way in which the practice curriculum has been assessed. The use of carefully devised practice studies is also advocated. Some programmes have struggled with the problem of formal grading in the practice curriculum. Other programmes have retained formal grading for the coursework curriculum while adopting a pass-fail framework for the practice curriculum. Whichever assessment approach is used, there is still a need to ensure that practice teachers have a central role in assessing performance of students during practice placements. Some educators find it very difficult indeed to give the power of assessment to practice supervisors. Still, if candidates are to demonstrate competence in professional practice then no one is better qualified to assess their performance than the practice teacher with whom they are most closely involved in day to day practice. Any alternative is likely to undermine the very purpose of the practice curriculum itself, namely to prepare intending workers for action in professional practice.

\section{Implications for professional practice}

One of the most important benefits to accrue from a carefully planned and executed practice curriculum is that candidates are helped to prepare for the uncertainties of professional practice. Most educational approaches tend to emphasise selected 'truths' and social principles which apply, given ideal conditions. Preparation for uncertainty is, therefore, an important goal in professional education. As professional education is concerned with licensing people and 'turning them loose on the unsuspecting public', so it is important that professional performance has been tested and examined under circumstances which may be less than ideal. Those who are responsible for professional education can be said to have a social, if not a moral obligation to ensure that minimum standards of performance in practice will have been achieved. The practice curriculum is where this type of examination can be addressed most directly.

A second implication for professional practice is that candidates will have demonstrated their ability to intervene in a variety of circumstances, whether with individuals or groups. The design of the practice curriculum should build in expectations that candidates will be tested in a variety of ways so as to address different practice demands. It is rarely the case that professional workers will be able to practise effectively using only one particular approach. The realities of practice are such that professional involvements with individuals and groups will be required, whether one thinks of dealings with clients or community groups, or of engagements with colleagues, teams and other professional workers. In all of these instances, good professional practice requires an ability to engage at different levels and with suitably different approaches. 
A third implication is that intending workers will have developed the capacity to assess how the organisations in which they work tend to influence their ability to perform in professional practice. It is also important that candidates have learned to take account of how the social policy environment shapes their practice and how they, in turn, can influence the development of social policies. Unless the practice curriculum has emphasised the organisational context and the social policy environment throughout the practice learning process, then workers are likely to make unhelpful distinctions between the work they do with clients and that which involves work with colleagues, managers and other professional groups. Furthermore, unless candidates learn how social policies are made and implemented in daily practice, they are unlikely to accept professional responsibility later for influencing and developing policies which more directly respond to important practice concerns (Rein, 1983).

A fourth implication is that intending professional workers will acquire competence to engage with others without having to resort to the abuse of interpersonal power and authority. Many workers have not been adequately tested in this area with the result that power and authority issues are frequently encountered in the course of professional practice. Whether concerned with direct practice with clients, or indirect practice with managers, colleagues and others on behalf of how one uses his or her own personal and professional authority (sic). Many authority conflicts have arisen because these issues have not received proper attention as part of professional education. The challenge is not, therefore, one of making such conflicts disappear. Instead, the challenge to professional education is concerned with helping intending workers to avoid the abuse of interpersonal power and authority in their relations with clients and colleagues.

A fifth implication for professional practice is that intending workers will demonstrate analytical rigor in the way that they engage in study, assessment and intervention planning processes with individuals and groups. Throughout this paper, attempts have been made to show how professional practice involves a rigorous analytical approach but that such an approach needs to emphasise applied learning and not simple reliance on theoretical abstractions. Unless the practice curriculum tests and extends a worker's ability to apply theoretical concepts to actual work demands, then professional education will have failed to achieve the most basic objectives. Effective practice requires that workers be able to respond to a variety of professional dilemmas, often encountered in the course of any working day. Professional education needs to equip workers to study these issues in an informed manner, to assess social problems in a detailed and systematic fashion, and to plan interventions which will empower others to overcome or ameliorate such problems in the most effective manner. It is in the practice curriculum where competence in this area of knowledge and skill is most readily addressed and examined.

A sixth implication for practice involves the ability of intending professionals to critically evaluate social research and to use basic evaluation methods to monitor and evaluate their own practice. Competence in this area helps to ensure that workers will continue to examine and develop their own professional practice. In this way, knowledge and skill development becomes an ongoing feature of professional practice. As workers endeavour to critically examine their own practice, so it is possible to see that services for clients and community groups will develop and improve. In a rapidly changing society, developments in professional practice must be seen as an essential feature of the claim to professional status. Any alternative to this argument simply relegates professional practice to a level of technical or occupational competence which is inconsistent with a claim to professional standing. The demands of professional practice are such that workers should be expected to keep abreast 
of the changing expertise of their profession. The ability to evaluate performance is therefore a minimum expectation in professional practice.

Finally, developing competence in each of the foregoing areas of knowledge and skill should assist professional workers to acknowledge and address their own continuing educational needs. This emphasises the importance of post-qualifying education and further reinforces the point that professional education involves a commitment to ongoing learning. As policies change and new methods of working are developed, so professional practice requires that new advances in knowledge and skill will be recognised and incorporated into one's existing framework. To assume that professional education is obtained fully at a given period in a worker's career is to misrepresent the very nature of practice learning. This is especially true in a rapidly changing society where the demands of professional practice are anything but static. Unless continuing education is recognised as a basic requirement of professional practice, then services available to individuals and groups will always be dependent on yesterday's knowledge and expertise.

Throughout this paper, we have argued that professional practice involves an active commitment to growth and change, whenever the demands of daily involvement with individuals and groups requires it. Perhaps the greatest implication to be drawn from all that has been said is that professional education has an obligation to the public at large to ensure that workers will continue to develop their professional practice to meet the changing needs of a changing society. In this way, social workers - as well as other professional workers - stand a greater chance of meeting the needs which they confront in their practice today. They will also be better equipped to address the issues which will confront them in practice tomorrow. The challenges to professional education have never been greater, but the prospects are encouraging for educators and practitioners alike, so long as careful attention is given to the place of supervised practice in the overall curriculum. It is for this reason that we argue for putting the baby back in the bathwater, to ensure that supervised practice learning continues to be the central feature of all professional education.

\section{References}

Ainsworth, F. (1981). The training of personnel for group care with children. In F. Ainsworth and L.C. Fulcher (Eds.) Group care for children: Concept and issues. London: Tavistock Publications.

Ainsworth, F. (1984). Planning for change. In T. Philpot (Ed.) Group care practice: The challenge of the next decade. Sutton, Surrey: Business Press International.

Bronfenbrenner, U. (1979). The ecology of human development. London: Harvard University Press.

Brown, R., Bute, S. \& Ford, P. (1986). Social workers at risk: The prevention and management of violence. London: MacMillan.

Casson, P. (1982). Social work courses: Their structure and content. London: Central Council for Education and Training in Social Work.

Kinloch, H. \& Fulcher, L. (1984). Report of the group care training project: 1979-1982. Barkingside, Essex: Dr Barnardo's / University of Stirling.

Knapp, M. (1985). The economics of social care. London: MacMillan.

Knowles, M. (1978). The adult learners: A neglected species. New York: Gulf Publications.

Livingstone, R. \& Benton, G. (1975). Early writings of Karl Marx. Harmondsworth, Middlesex: Penguin.

Millham, S., Bullock, R. \& Hosie, K. (1980). Learning to care: The training of staff for residential social work with young people. Guildford, Surrey: Gower Publishing.

Osborne, A. (1983). Distance learning and the social services. London: Leverhulme Trust.

Rangihau, J.T.R. (1986). Puao-te-ata-tu: Report of the Ministerial Advisory Committee on a Maori perspective for the Department of Social Welfare. Wellington, New Zealand: Government Printing Office.

Rein, M. (1983). From policy to practice. London: MacMillan.

Scull, A. (1977). Decarceration. Englewood Cliffs, New Jersey: Prentice Hall.

Syson, L. (1981). Learning to practise. London: Central Council for Education and Training in Social Work. 